Spring 1982

\title{
An Examination of the Psychometric Properties of Some Commonly Researched Individual Differences, Job, and Organizational Variables in Two Cultures
}

\author{
Harry J. Martin \\ Cleveland State University, h.martin@csuohio.edu \\ Uma Sekaran \\ Southern Illinois University
}

Follow this and additional works at: https://engagedscholarship.csuohio.edu/busman_lab_facpub

Part of the Management Information Systems Commons, and the Management Sciences and Quantitative Methods Commons

How does access to this work benefit you? Let us know!

\section{Publisher's Statement}

(c) 1982 Palgrave Macmillan

\section{Original Citation}

Sekaran, U. \& Martin, H. J. (1982). An Examination of the Psychometric Properties of Some Commonly Researched Individual Differences, Job, and Organizational Variables in Two Cultures. Journal of International Business Studies, 13, 51-65. doi: 10.1057/palgrave.jibs.8490538

\section{Repository Citation}

Martin, Harry J. and Sekaran, Uma, "An Examination of the Psychometric Properties of Some Commonly Researched Individual Differences, Job, and Organizational Variables in Two Cultures" (1982). Management And Labor Relations. 20.

https://engagedscholarship.csuohio.edu/busman_lab_facpub/20

This Article is brought to you for free and open access by the Browse Business Faculty Books and Publications by Topic at EngagedScholarship@CSU. It has been accepted for inclusion in Management And Labor Relations by an authorized administrator of EngagedScholarship@CSU. For more information, please contact library.es@csuohio.edu. 


\title{
AN EXAMINATION OF THE PSYCHOMETRIC PROPERTIES OF SOME COMMONLY RESEARCHED INDIVIDUAL DIFFERENCES, JOB, AND ORGANIZATIONAL VARIABLES IN TWO CULTURES
}

\author{
Uma Sekaran, Southern Illinois University \\ Harry J. Martin, Cleveland State University
}

This article was originally published in:

Sekaran, U., \& Martin, H. J. (1982). An Examination of the Psychometric Properties of Some Commonly Researched Individual Differences, Job, and Organizational Variables in Two Cultures. Journal of International Business Studies, 13, 51-65.

Post-print standardized by MSL Academic Endeavors, the imprint of the Michael Schwartz Library at Cleveland State University, 2012

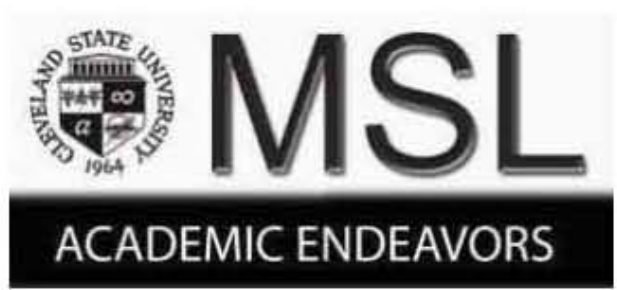




\title{
AN EXAMINATION OF THE PSYCHOMETRIC PROPERTIES OF SOME COMMONLY RESEARCHED INDIVIDUAL DIFFERENCES, JOB, AND ORGAIVIZATIONAL VARIABLES IN TWO CULTURES
}

\author{
UMA SEKARAN* \\ Southern IIIinois University \\ HARRY J. MARTIN** \\ Cleveland State University
}

\begin{abstract}
This study examines the transferability and applicability of selected measures of individual differences, job, and organizational climate factors across two cultures. Ques. tionnaires were administered to a sample of 267 white-collar bank employees in the U.S. and 307 bank employees in India. The individual difference dimensions examined were four manifest needs, sense of competence, and locus of control. The job factors included variety, autonomy, identity, and feedback. The organizational climate factors related to communication, stress, participation in decision making, and self-esteem from the workplace. The data were analyzed for internal consistency, dimensionality, and criterion-related validity. The results showed that the job and organizational climate measures were more reliable and were related more consistently to the criterion measures than the individual difference measures, both within and across cultures. The results suggested that psychometrically sound measures may be transferable to other cultures.
\end{abstract}

A major concern in cross-cultural research, especially in the psychological and organizational behavior areas, is the applicability of measures developed in one culture to another. Some behavioral scientists are quite pessimistic about the utility of cross-cultural studies for making significant theoretical advances [Nath 1968; Roberts 1970; Roberts and Snow 1973]. Yet, the need for cross-cultural studies is great, especially given the rapid industrialization of the developing countries, the continued expansion of international business operations, and the increased use of indigenous labor by foreign companies [Zucher 1968]. An important prerequisite for the advancement of cross-cultural organizational research, however, is the establishment of the psychometric properties of organizational measures which are applied cross-culturally.

There are 6 primary methodological issues that deserve special attention while engaging in developing and/or validating measures cross-culturally. They are:

1. The transcultural nature of the variables investigated. In other words, the concepts and their meaning should be applicable between cultures in terms

* Uma Sekaran is Associate Professor of Administrative Sciences at Southern Illinois University. She received her M.B.A. from the University of Connecticut and her Ph.D. from the University of California at Los Angeles. Dr. Sekaran has twenty years of banking experience and is engaged in extensive research in the banking industry in India and the U.S. Her publications have appeared in Administrative Science Quarterly, Academy of Management Journal, International Review of Applied Psychology, Group and Organization Studies, and other journals.

* Harry J. Martin is Assistant Professor of Management in the James J. Nance School of Business Administration at Cleveland State University. He received his Ph.D. from Southern Illinois University at Carbondale and has co-authored a number of articles in the areas of leadership and psychological assessment. He is currently investigating the development of power and prestige orders in task-oriented work groups. 


\section{AN EXAMINATION OF THE PSYCHOMETRIC PROPERTIES}

of cultural values, taboos, political consideration, patterns of interpersonal relations, and other factors which may directly or indirectly exert their influence on the frame of reference, and, hence, the meaning of concepts to the respondents [Hudson, Baraket, and LaForge 1959].

2. The problem of instrumentation is also said to be magnified when studies are conducted across national boundaries [Roberts and Snow 1973]. The main concern here is that even given the best translations, the semantic value of particular words and phrases may differ appreciably across 2 cultures leading to different responses and interpretation of meanings. Thus, testing the instrument (developed in one culture) in other cultures becomes crucial.

3. Even if cross-culturally comparable instruments are available, they may only ensure stimulus equivalence. In order to ensure response equivalence, one also needs a comparable process of data collection [Hudson et al. 1959]. This includes establishing rapport between researcher and respondents, uniform methods of task presentation, and equivalence in motivation and goal orientation of both the researcher and the respondents. [For example see Weber and Cook 1972] In short, ideally, the same researcher should undertake data collection in both cultures adopting uniform procedures.

4. Sampling design is another vital issue. It is important that the sample in the 2 or more cultures be matched for basic socioeconomic, organizational, and other vital characteristics that may affect the research findings [Hudson et al. 1959].

5. Timing of data collection in the different cultures is also important. Data should be collected in all cultures within a reasonable period of time and not much time should elapse between data collection periods [Hudson et al. 1959].

6. Last, issues in regard to data analysis are critical. Although correlational approaches may reveal patterns of significant similarities, they may be too gross for testing concepts in different cultures. Multivariate factor analysis and item analysis have been advocated as suitable data analytic techniques for capturing subtle differences in how concepts are absorbed in different cultures [Hudson et al. 1959].

Trans-Cultural Variables Useful for Cross-Cultural Organizational Research
Evidence is accumulating regarding variables in the area of personality dynamics which have potential for classification as universals and which may not be particularistic to specific cultures [Hudson et al. 1959; Maslow 1954; McClelland 1962; Whitting \& Child 1953; Wiggins 1979]. More recent work by Sekaran [1981] has indicated that job and organizational factors that transcend national boundaries are important factors in organizational research.

Thus, it is important to assess the cross-cultural adequacy of measures that have been used frequently to investigate individual difference variables (such as, the Protestant work ethic and manifest needs in the work setting), job characteristics (such as, job variety and identity), and organizational climate factors (such as, communication and participation in decision making). If methodologically sound studies can show that certain concepts and measures are applicable between or across cultures, then further research can proceed to develop better theories for use by multinational corporations (MNCs) to assist them in functioning more effectively across national boundaries.

The present study was conducted to determine the cross-cultural transferability and applicability of selected concepts and measures tapping some of the most commonly investigated personality, job, and organization factors in U.S. organi- 
zational research. Establishing the reliability and validity of the measures for cross-cultural application would, among other things, make a significant contribution to the literature of international business research in the measurement area.

Thus, this study sought to examine the psychometric properties of 5 sets of measures tapping several organizational, job, and personality dimensions. The 6 methodological issues of concern in cross-cultural research discussed earlier, were addressed in this study. To avoid problems of transliteration, 2 cultures which have English as the medium of instruction in schools and as the official language were chosen so that identical questionnaires could be administered. To ensure stimulus and response equivalence, the same researcher administered the questionnaires to groups of 25 to 30 respondents in both cultural settings and followed uniform methods of introduction, task presentation, and termination of the session. Care was taken to obtain samples from organizational settings in both cultures that were as closely matched as possible in terms of industry, technology, and levels of employees selected. Data were collected in November - December of 1978 in the U.S. and in May 1979 in India, thus avoiding timing problems. Multivariate methods were used for data analysis.

The 2 cultures selected for the study were the United States and India. India as the cultural setting for cross-validating U.S. instruments is appropriate not only because English is the official language of India but also because many MNCs operate in India. Validating the concepts and measures in this developing country with methodological rigor would be useful for conducting further cross-cultural research to identify problem areas and offer solutions.

Front office and support personnel (tellers, clerks, loan officers, bookkeepers, accountants, and their supervisors) from 12 midwestern U.S. banks and 9 banks in the middle and southern parts of India were administered virtually identical ques. tionnaires. (Only the currency denominations for assessed income were changed.) The employees who responded to the questionnaires were representative of lower level bank employees. The sample included 267 U.S. and 307 Indian whitecollar employees. The mean age of the respondents was nearly the same in both cultures (U.S., 35; India, 37). Twenty-one percent of the respondents had college degrees in the U.S., as opposed to 91 percent in India. Indian banks do not, as a general rule, recruit non-degree holders, and hence this disparity is understandable. Eighty-three percent of the U.S. respondents were females, in contrast to 18 percent in India because the proportion of women working outside of the home is comparatively much smaller in India than in the U.S. [See Statistical Outline of India 1980.] Approximately 65 percent of the U.S. respondents and 73 percent of the Indian respondents were married. Although there are some differences in the demographic composition of the workforce, all subjects were white-collar employees in banking systems. All banks shared the same mediating technology and all operated under a common policy umbrella established by either the U.S. or Indian central bank.

The variables of primary interest in this study included 1) the 4 organizational climate factors of stress, communication, participation in decision-making, and self-esteem from the job setting; 2 ) the 4 job characteristics of variety, autonomy, identity, and feedback; and 3) several individual differences dimensions which included (a) sense of competence, (b) four manifest needs, and (c) locus of control. A brief description of these measures, their origin, and the number of items in each is provided in Table 1. These measures have been reported to possess adequate reliability and validity by their developers and have been used frequently in organizational research in the U.S. 


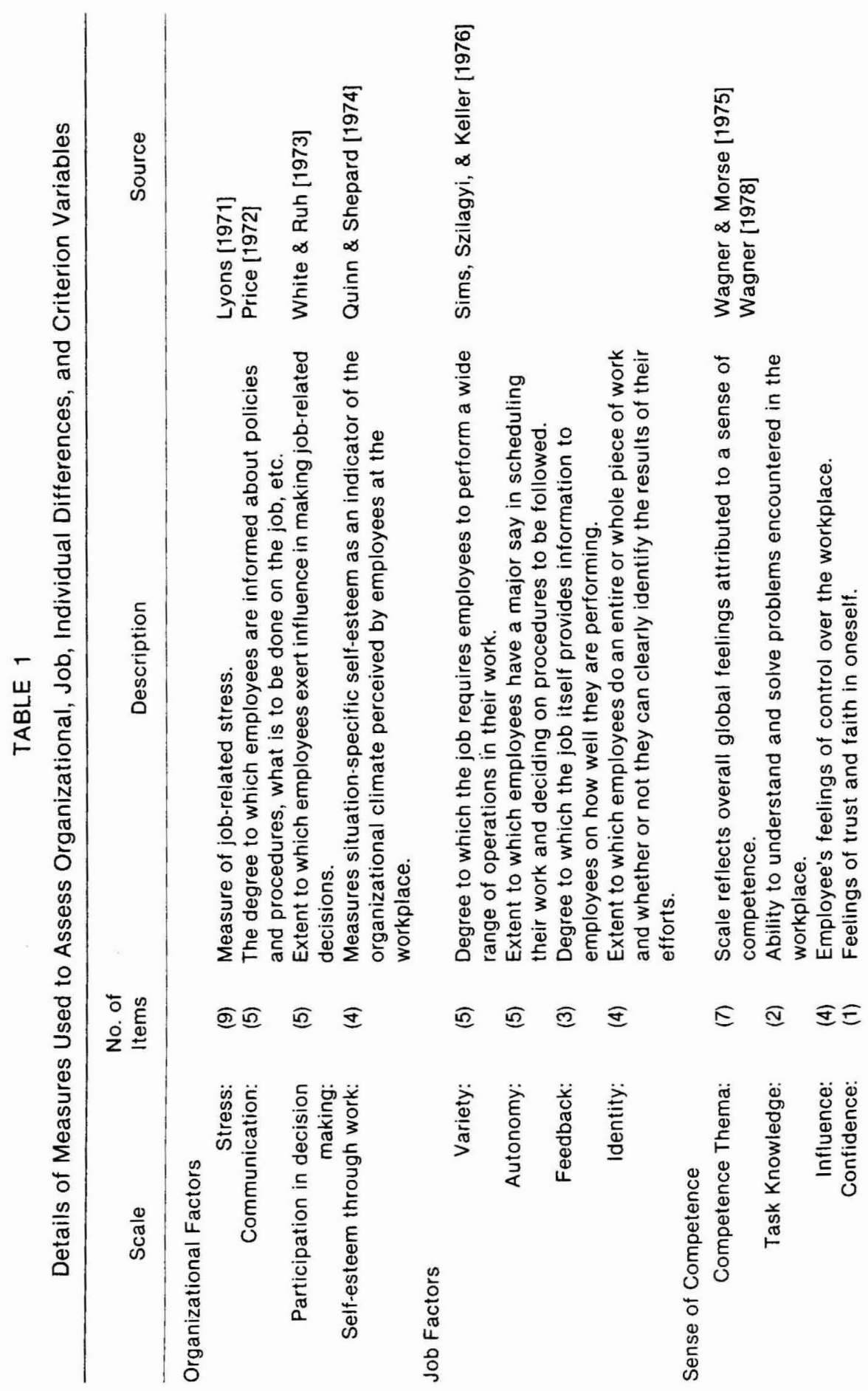



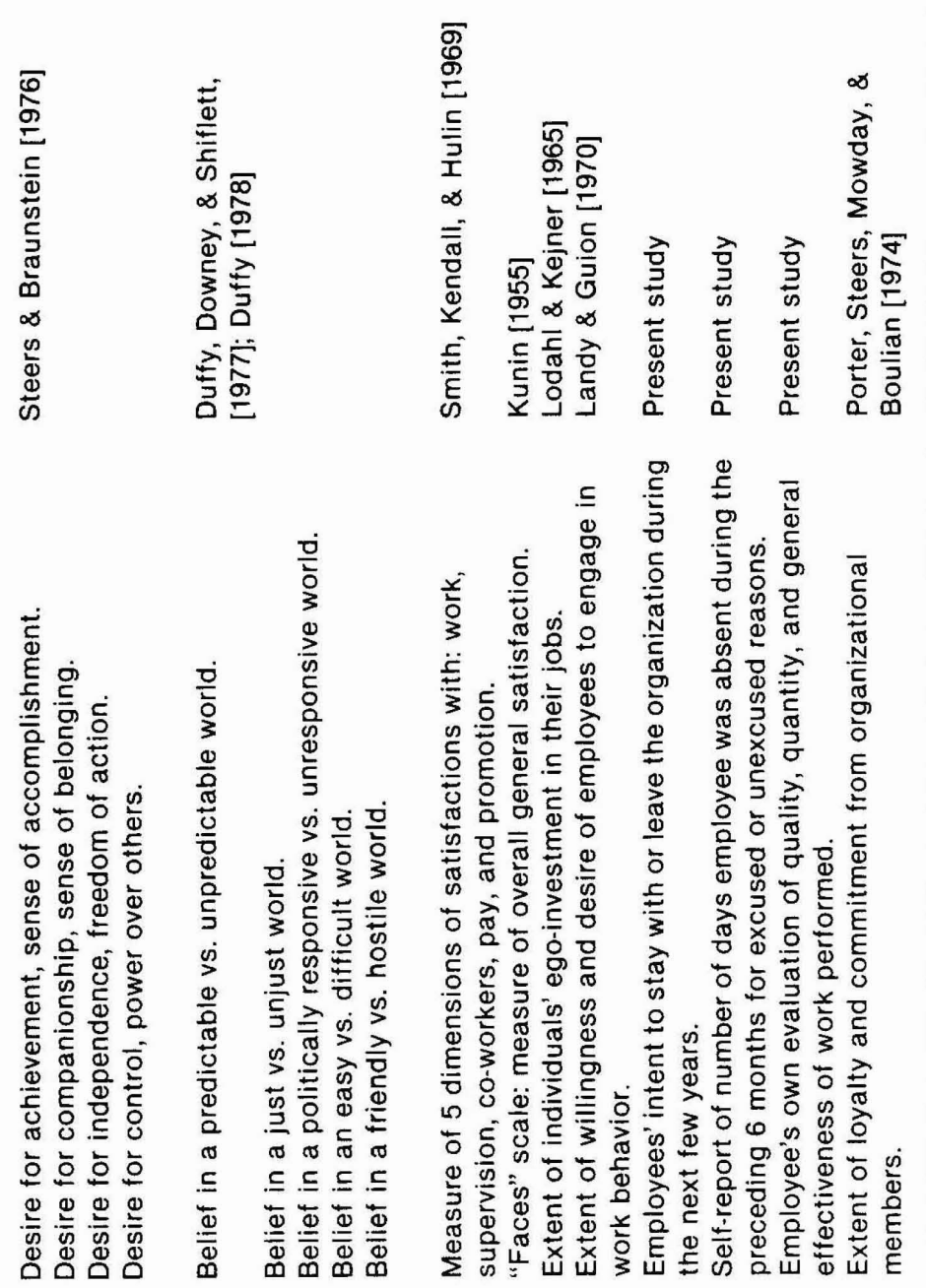

可鱼西贾

ले त्रत्रत्रल




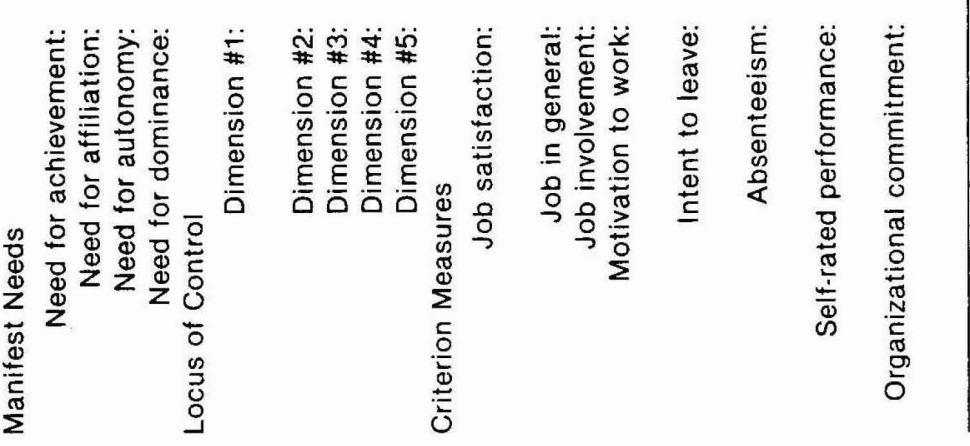


\section{AN EXAMINATION OF THE PSYCHOMETRIC PROPERTIES}

In addition to these variables of primary interest, several outcome variables found to be associated commonly with these primary variables were used to test the criterion-related validity of the instruments. The cross-cultural validity and applicability of some of the criterion variables have already been examined and established. [For example: Sekaran 1981.] These criterion variables related to 5 facets of job satisfaction, general overall job satisfaction, job involvement, motivation to work, intent to leave, absenteeism, self-rated performance, and organizational commitment. They are also described in Table 1. All items, with the exception of the 2 items for absenteeism, were measured either on a 7- or a 5-point Likert-type scale.

Thus, 4 organizational climate factors, 4 job characteristics, 3 individual differences dimensions, and several aspects of satisfaction, job involvement, motivation to work, intent to leave, absenteeism, performance, and organizational commitment were included in the questionnaire developed for this study.

Data Collection

Data Analysis
Questionnaires were administered to small groups of 20 to 30 employees in the banks' conference rooms. The same researcher administered the questionnaire in all 21 organizations and followed identical procedures regarding introduction of self and survey. Respondents took approximately 45 minutes to complete the questionnaire.

To evaluate the psychometric properties of the scales of primary interest and determine their adequacy both within and across cultures, aspects of reliability and dimensionality as well as validity were examined. More specifically, criteria for evaluation focused on (a) internal consistency reliability, (b) factor structure, (c) criterion-related validity within culture, and (d) differences in criterion-related validity across cultures. In view of the differences in the sex composition and educational level of the employees in the two cultures, selected analyses were also conducted on stratified subsamples within each culture.

Internal consistency. The internal consistency reliability of a scale reflects the degree to which it samples the content domain which it is designed to represent. The present analysis used Cronbach's Coefficient Alpha which can be interpreted as the average correlation between a scale and another scale of the same length drawn from the same content domain [Cronbach 1951]. If the coefficient is low, then the scale is not internally consistent and does not sample adequately from the content area which it was designed to measure. An arbitrary cut-off point was set at $r_{x x}=0.60$ for minimally acceptable internal consistency reliability.

Factor structure. Because specific subdimensions have been hypothesized for each of the 5 sets of scales investigated in this study, the comparability of factor structures between samples was assessed using confirmatory rather than exploratory factor analytic procedures [Gorsuch 1974; Jöreskog 1969]. Specifically, the intercorrelation matrix of items in each of the 5 groups was subjected to a multiple-group factor analysis ${ }^{1}$ [Gorsuch 1974]. By using this technique, the adequacy with which scale items form previously hypothesized factors was evaluated within cultures as well as differences assessed between cultures. The dimensionality was assessed using a common factor model (rather than a principal components approach) and initial communality estimates were obtained using squared multiple correlations.

Criterion-related validity. To evaluate criterion-related validity, cross-validated multiple-regression procedures were employed. This technique was used to (a) provide an average measure of the degree of association $\left(R^{2}\right)$ between a set of predictor variables and the criterion measures within each culture as well as (b) provide a measure of the amount of shrinkage in associations between sets of 


\section{AN EXAMINATION OF THE PSYCHOMETRIC PROPERTIES}

variables across cultures. This analytic technique was an ideal tool for the present analyses because a large number of relationships can be condensed into a few concise, easily comparable statistics. Also, no assumptions are necessary when $R^{2}$ s are used merely to describe relationships [Cohen and Cohen 1975]. Even if tests of significance were involved, which was not the case here, numerous studies have shown that these statistics are impervious to failure of distributions and other assumptions [For example: Cohen and Cohen 1975].

In the analysis, each set of subscales in the 5 content areas of interest was used to predict the 12 criteria shown in Table 1 . To evaluate criterion-related validity within cultures, multiple-R's were averaged across the 12 criteria for each set of predictors.

Differences across cultures. To assess cross-cultural differences in criterionrelated validity, a double cross-validation design was employed [Kerlinger and Pedhazur 1973; Mosier 1951]. The regression weights derived previously for each sample were applied to the other culture to determine the adequacy of prediction across groups. The cross-validated multiple-R's were then averaged over the 12 criteria and taken as an estimate of the validity of using a given set of predictors across cultures. If the resulting multiple-R's show little shrinkage, this would argue in favor of the psychometric similarity of the predictor set across cultures. Whereas the cross-validated multiple regression analysis provides useful summary information regarding the dimensions and their performance across cultural boundaries, specific information regarding particular subscales for each criterion variable is lost. In order to acquire more detailed information concerning the individual subscales and their relationships with the criteria, zero-order predictor-criterion correlations were obtained for each subscale and the number of significant differences in these correlations between cultures examined [Hays 1973; McNemar 1962], as well as the types of criteria for which these differences occurred. Of particular interest was the number of significant $(p<.05)$ differences in the coefficients between cultures. If the number is low and can be explained by situational factors particular to the cultural environment, we can have more confidence in the transferability of concepts and measures across national boundaries.

In summary, the present study analyzed (1) internal consistency reliability, (2) factor structure or dimensionality, (3) criterion-related validity, and (4) zero-order predictor-criterion correlations to assess the adequacy of the scales within cultures as well as their transferability across cultures.

Initial analyses were conducted on various subsamples to assess the impact of differences in the sex composition and educational level of the employees between the 2 cultures. Results indicated that there were no substantial differences between groups. Therefore, results reported here are for the entire sample from each culture.

The findings regarding reliability for each of the 5 sets of scales are presented in Table 2. As can be seen, within both the U.S. and Indian cultures, the scales measuring organizational factors and job factors had higher reliability than those scales measuring aspects of sense of competence, manifest needs, and locus of control. This holds true even when the reliability coefficients are corrected for the length of the scale. In the U.S. sample, the average coefficient for the organiza. tional factors scales was .82 and for the job factors scales the average coefficient was .76. The subscale coefficients for each of these 2 dimensions were acceptable. In contrast, only the competence and influence subscales had acceptable reliabilities for sense of competence (average $r_{x x}=.59$ ) and only the need for dom- 





inance subscale achieved acceptable reliability in the manifest needs set (average $\left.r_{x x}=.41\right)$. None of the locus of control subscales met the criterion set for acceptable reliability (average $r_{x x}=.41$ ).

Similar results were obtained for the Indian sample. All of the organizational factors scales met the criterion (average $r_{x x}=.78$ ). The job factors set also performed adequately (average $r_{x x}=.63$ ); however, the feedback and identity subscales were slightly below the consistency criterion. For the sense of competence set (average $r_{x x}=.43$ ) only the competence subscale reached an acceptable level of consistency and none of the manifest needs (average $r_{x x}=.31$ ) or locus of control (average $r_{x x}=.34$ ) subscales reached acceptable levels.

Table 2 also provides internal consistency reliabilities for each set of scales when all items in a set are taken together without consideration of subscale membership. These results are identical to those discussed previously with the organizational factors, job factors, and sense of competence scales showing acceptable reliability in both cultures. On the other hand, the locus of control scales performed poorly in both cultures. This procedure cannot be meaningfully applied to the manifest needs scale.

In summary, those dimensions which relate to aspects of the organization and the job possessed somewhat greater internal consistency than those scales relating to individual differences. In addition, this pattern tended to generalize across cultures. With the exception of the competence thema subscale, all of the organizational and job factors subscales were more reliable than the personality dimensions in both the U.S. and Indian cultures. The question of whether this result is due to an inadequacy in measurement or a problem with the constructs themselves cannot be determined from these data and awaits future investigation.

Table 2 also includes a summary of the results obtained from a multiple-group confirmatory factor analysis [Gorsuch 1974] conducted for each set of subscales separately by culture. ${ }^{2}$ The table indicates the items in each subscale which did not pass the dimensionality test - that is, each of these items had loadings on 1 or more factors which were greater than its loading on the hypothesized factor. The original item numbers not passing this test indicated on the table correspond to those in the original publications as cited in Table 1.

Within the U.S. sample, all subscales from the organizational and job factors dimensions as well as the sense of competence subscales performed quite well. In contrast, all but 2 of the manifest needs and all locus of control subscales performed poorly. The need for dominance subscale was the only manifest need scale with both acceptable reliability and adequate dimensionality.

In the Indian sample, the results were similar. The organizational factors sub. scales performed well, along with the job factors scales. An exception here may be the variety subscale where only 2 of the 5 items loaded on the proper factor. The sense of competence scales, though possessing low internal consistency, did factor adequately. In contrast, all of the manifest needs items failed to factor properly and major difficulties were evident with the locus of control items.

In summary, the hypothesized factor structure of the organizational factors and sense of competence subscales received support using the multiple-group confirmatory factor analysis method. The job factors subscales were confirmed in the U.S. sample, but the variety subscale did not factor well in the Indian sample. Last, little support was obtained for the hypothesized factor structure of the manifest needs or locus of control subscales in either culture. These findings roughly parallel the reliability analysis in that those scales which relate to aspects of the job or the organization performed better than those scales which related to aspects of the individual's personality. This pattern was evident in both cultures. 
Criterion-Related Validity
Cross-validated multiple regression analyses were performed for each of the 12 criterion variables for the 2 samples; however, Table 3 presents only data averaged across the 12 criteria. $^{3}$ The initial multiple-R's represent the average degree of predictability for the 12 criteria based upon regression equations derived separately from each sample. The adjusted multiple-R's are the initial multiple-R's corrected for shrinkage within the same culture. The cross-validated multiple-R's represent the degree of shrinkage that was observed across cultures. The adjusted multiple-R's were obtained for each criterion using standard shrinkage formulas [for example: Cohen and Cohen 1975; Olkin and Pratt 1958] and then averaged.

Within the U.S. sample, it can be seen that the average amount of explained variance was small (approximately 5 percent for the manifest needs scales) to, perhaps, moderate (approximately 18 percent for the sense of competence scales). This lack of predictability may be expected partly because of the low number of predictors and lack of sophistication of the regression models. Despite the low magnitude of the multiple-R's, the organizational factors, job factors, and sense of competence dimensions accounted generally for 2 to 3 times the criterion variance when compared with the manifest needs and locus of control dimensions. The lower performance of these scales parallels the pattern of results that was observed when evaluating their internal consistency and factor structure.

Within the Indian sample, the amount of explained variance was, again, small (3.6 to 10.9 percent) and followed the same pattern observed in the U.S. sample. The organizational factors, job factors, and sense of competence dimensions accounted for approximately twice the criterion variance as the manifest needs and locus of control dimensions. Also, the shrinkage of the multiple-R's within this culture was about the same as that observed in the U.S. sample.

Across cultures, comparisons were made concerning (a) differences in the magnitude of the coefficients and (b) the amount of shrinkage observed during crossvalidation. Comparing the magnitude of initial and adjusted multiple-R's between cultures, the sense of competence and locus of control coefficients were somewhat lower in the Indian sample relative to the coefficients obtained for the other dimensions. In contrast, little difference in the magnitude of the coefficients was noted when the organizational factors, job factors, or manifest needs scales were used as predictors.

The amount of shrinkage in the cross-validated multiple-R's was also used to assess cultural differences. Initially, it was noted that there was very little shrinkage in the coefficients across cultures. This is somewhat encouraging given the cultural diversity of the 2 populations from which the present samples were drawn. Specifically, 2 trends were noted in the data. First, the shrinkage for the U.S. sample when applying regression weights derived from the Indian sample was greater (an average reduction of 3.5 percent) than when the U.S. coefficients were applied to the Indian sample (an average shrinkage of 2.2 percent). Second, it was noted that in the U.S. sample, the job factors, sense of competence, and locus of control dimensions experienced twice as much shrinkage as the organizational factors and manifest needs scales. In general, these results suggest a high degree of psychometric similarity in the constructs as they relate to the criterion measures across the samples used in this study.

In summary, the multiple regression analysis led to the following conclusions: (a) there was very little shrinkage in the multiple-R's within each culture; (b) for both the U.S. and Indian samples, the organizational factors, job factors, and sense of competence dimensions possessed higher criterion-related validity compared with the manifest needs and locus of control dimensions; and (c) finally, the overall shrinkage in the cross-validated multiple-R's between cultures was slight, though somewhat larger for the U.S. sample on the job factors, sense of competence, and locus of control dimensions. 
TABLE 3

Initial, Adjusted, and Cross-Validated Multiple Regression Coefficients Averaged Over 12 Criteria for U.S. and Indian Samples

\begin{tabular}{|c|c|c|c|c|c|c|}
\hline Dimension & & Initial Multi-R & Adjusted Multi-R & $\begin{array}{c}\text { Cross-Validated } \\
\text { Multi-R }\end{array}$ & $\begin{array}{c}\text { Shrinkage } \\
\text { Within Culture } \\
\text { (percent) }\end{array}$ & $\begin{array}{c}\text { Shrinkage } \\
\text { Across Cultures } \\
\text { (percent) }\end{array}$ \\
\hline & U.S.: & .35 & .33 & .31 & 1.4 & 2.6 \\
\hline . & India: & .33 & .30 & .29 & 1.9 & 2.5 \\
\hline \multicolumn{7}{|l|}{ Job Factors } \\
\hline \multicolumn{7}{|c|}{ Sense of Competence } \\
\hline & U.S.: & .42 & .40 & .36 & 1.6 & 4.7 \\
\hline & India: & .31 & .28 & .28 & 1.8 & 1.8 \\
\hline \multicolumn{7}{|l|}{ Manifest Needs } \\
\hline & U.S.: & .23 & .19 & .18 & 1.7 & 2.0 \\
\hline & India: & .23 & .19 & .18 & 1.7 & 2.0 \\
\hline
\end{tabular}

Note: Although these coefficients cannot be tested directly for significance, a multiple-R of .19 is significant at $p<.05$ and a multiple-R of .25 is significant at $p<.01$ with 4 and 261 degrees of freedom. 


\section{AN EXAMINATION OF THE PSYCHOMETRIC PROPERTIES}

Zero-order Predictor-Criterion Correlations

DISCUSSION
Of the 252 pairs of bivariate correlations examined, only 36 (14 percent) showed significant differences across the two cultures. Within each culture, the same scales that showed high reliability and validity in the earlier analyses also pro. duced a good number of significant bivariate relationships. In short, the bivariate analysis yielded practically the same patterns as the multivariate analysis.

It is of interest that the JDI Supervision scale and the JDI Pay scale were the only 2 criteria that differed consistently across the subscale dimensions. In all, these 2 criterion variables accounted for over half ( 53 percent) of the significant differences in the bivariate relationships.

From the assessment of the 5 sets of scales on their internal consistency, factor structure, and criterion-related validity across 2 cultures, the following conclusions can be drawn. First, as a group, the organizational factors, job factors, and sense of competence scales showed greater adequacy as compared with the manifest needs and locus of control scales. Second, very few differences existed between the 2 cultures in their response to these scales. Third, with regard to specific subscales, examination of the data suggests the following: (a) use of the organizational factors subscales is appropriate for both cultures; (b) the variety and autonomy job factors subscales are appropriate for both cultures - however, the feedback and identity subscales may not be appropriate for the Indian culture; (c) for the sense of competence dimension, the competence thema subscale is appropriate for both cultures - however, the influence subscale should be limited to U.S. samples and the task knowledge and confidence subscales do not appear to be useful in either culture. Thus, the recommended 14-item short measure seems unable to measure adequately all the dimensions of the construct; (d) finally, the data suggest that the manifest needs and the 15-item locus of control subscales do not meet the minimum requirements as reliable and valid measuring instruments and should be used with extreme caution in both cultures.

This study set out to examine the cross-cultural generalizability of 4 organizational climate variables, 4 job characteristics, and 3 individual differences dimensions used frequently in organizational research. The examination of internal consistency reliability, factor structure, and criterion-related validity both within and across a sample of U.S. and Indian bank employees revealed that the instruments tapping the organizational climate and job variables were psychometrically superior to those that measured the individual differences variables. This was generally true for both cultures.

A few points are of particular interest. Differences in educational levels and the sex composition of the two samples did not bias the results as evidenced by the results of analyses controlling for these differences; however, the reliabilities of the measures, overall, were slightly lower for the Indian sample. Whether this can be attributed to the differences in the extent of mechanization, and/or English being the primary spoken language in one culture, or to some other reason, cannot be established from this field study. The surprising finding is that the job and organizational climate measures developed in the U.S. are transferable to India. In sum, the use of all 4 organizational climate dimensions (stress, communication, participation in decision making, and self-esteem from the workplace) appears to be appropriate in both cultures. Whereas all 4 of the job factors scales seem to be adequate to employees' job perceptions in the U.S. sample, the feedback and identity subscales may need to be strengthened for use in India. Of the 3 individual differences dimensions, only sense of competence performed adequately. Neither the manifest needs nor the locus of control measures reached acceptable levels of reliability or validity in either culture. If these measures are to be used in future studies, their adequacy must be more firmly established. The results also suggested that if a short version of sense of competence is required, only the competence thema subscale should be used. 
An important finding of this study is that measures developed in the U.S. to tap aspects of the job and organization appear to be transferable to work environments in the Indian culture. Thus, merely because a measuring instrument has been developed in one culture does not necessarily mean a priori that it cannot be used successfully in another. This is not to suggest that cultural differences are not important, but that concepts and psychometrically sound instruments developed in one culture may be transferable to another without the necessity for major revision, provided the 6 major methodological issues detailed at the beginning of this article are taken into consideration. The findings in this study lead to the following recommendations for those conducting cross-cultural organizational research. First, check the reliability and validity of the instrument in the culture for which it was developed using a sample which is representative of the target population. If it displays adequate psychometric performance, administer the scale to a pilot sample in the culture of interest. If the scale continues to show adequate performance, then one may save the trouble and expense of developing new instruments for each culture when such additional effort may not be necessary; however, if the instrument performs poorly in the first step, as was the case in this study with the manifest needs and locus of control scales when applied to U.S. bank employees, then cross-cultural generalizability is unlikely.

The failure of the manifest needs and locus of control measures is quite unfortunate. It was hoped that the data could be used to compare situational versus intrapersonal variables across cultures. Because the latter scales performed poorly in the U.S. sample as well as in the Indian sample, it cannot be concluded from these data whether the situational (job and organization climate) variables possess greater transcultural generalizability than the personality or individual differences variables. Resolution of this question appears to depend on the development of concepts and measures of personality that are reliable and valid within a culture before they can be assessed across cultural boundaries.

A further finding of interest is the number of significant differences observed in the bivariate correlations between the 2 cultures. The number was quite small and occurred mainly for the criterion variables of satisfaction with supervision and pay. This result points to the importance of careful assessment of the cultural differences inherent in the organizational systems with which one is dealing. With regard to satisfaction with supervision, it has been shown that Indian organizations are more authoritarian in nature as compared with their more egalitarian counterparts in the U.S. [Meade and Whittaker 1967]. Given these important differences in the very nature and style of supervision between the U.S. and Indian systems, it is natural to observe changes in the relationships between cultures regarding response to supervision. With regard to satisfaction with pay, the pay system changes markedly between the 2 cultures, especially in the banking industry. Whereas bank employees in the U.S. are paid differentially based on merit, the Indian banks, in accordance with the National Bank Tribunal Award, pay all their employees at any particular job level uniformly with fixed graduated, annual pay raises. Wvith such fundamental cultural differences in the reward system, one would expect significant differences in bivariate relationships. It is important that such cultural differences in the organizational systems be understood so as to better design studies and interpret their results.

In summary, the results of this study indicate strongly the transferability and applicability of several psychometrically sound measures frequently used in organizational research. Cross-cultural research can thus proceed in making important theoretical advances for practical application, while better instruments are developed for the less reliable and valid measures needed to tap individual differences and organizational concepts. These endeavors would be particularly useful to MNCs operating in other cultures. 


\section{AN EXAMINATION OF THE PSYCHOMETRIC PROPERTIES}

FOOTNOTES 1. Confirmatory maximum likelihood factor analysis [Jöreskog 1969; Jöreskog and Lawley 1968; Jöreskog and Sörbom 1979] is another potentially useful technique for the analysis of such data; however, the computer programs necessary to conduct this analysis [COFAMM, Jorreskog and Sörbom 1979; RMLFA, Jöreskog and Gruvaeus 1967] were not available to the authors. Because exploratory maximum likelihood procedures were accessible, investiga. tion of the correlation matrices employed in the multiple-group analysis was undertaken using this method. Results were essentially the same as those obtained using the multiplegroup method, and the residual correlation matrices were quite similar.

2. The decision as to whether the factors should be treated as correlated or orthogonal in nature was made empirically. This was accomplished through examination of the factor correlations obtained in the present study as well as by selecting the approach which yielded the best factor structure. Based on this approach, subscales which form the organizational factors, job factors, sense of competence, and manifest needs dimensions were treated as correlated factors and the factor pattern matrix was evaluated. Subscales which form the locus of control dimension were treated as orthogonal factors and the orthogonal factor matrix was evaluated. Because multiple-group factor analysis specifies a sufficient num. ber of restrictions on the factor space, the solution is unique and only one factor position will satisfy the fixed parameters. Therefore, no rotation is involved.

3. Although the regression analysis was conducted separately for each of the 12 criteria, only the averaged multiple-R's are reported. This was done in order to (a) reduce the num. ber of comparisons and amount of data to manageable proportions and (b) present the findings across a diverse range of outcome variables commonly investigated in organiza. tional research so as to minimize unique or unusual effects specific to any one measure.

Cohen, J., and Cohen, P. Applied multiple regression/correlation analysis for the behavioral sciences. Hillsdale, NJ: Lawrence Erlbaum Associates, 1975.

Cronbach, L. F. "Coefficient alpha and the internal structure of tests." Psychometrika, 1951, pp. 297-334.

Duffy, P. J.; Downey, R. G.; and Shiflett, S. "Locus of control: Dimensionality and predictability using Likert scales." Journal of Applied Psychology, 1977, pp. 214-219.

Duffy, P. J. Personal Communication, 6 April 1978.

Gorsuch, R. L. Factor analysis. Philadelphia: Saunders, 1974.

Hays, W. L. Statistics for the social sciences, 2 nd ed. New York: Holt, Rinehart, \& Winston, 1973.

Hudson, B. B.; Baraket, M. K.; and LaForge, R. "Problems and methods of cross cultural research." Journal of Social Issues 15, no. 3 (1959), pp. 5-19.

Joreskog, K. G. "A general approach to confirmatory maximum likelihood factor analysis." Psychometrika, 1969, pp. 183-202.

, and Gruvaeus, G. RMLFA-A computer program for restricted maximum likelihood factor analysis. Research Memorandum 67-21. Princeton, NJ: Educational Testing Service, 1967.

Jöreskog, K. G., and Lawley, D. N. "New methods in maximum likelihood factor analysis." British Journal of Mathematical and Statistical Psychology, 1968, pp. 85-97.

Jöreskog, K. G., and Sörbom, D. Advances in factor analysis and structural equation models. Cambridge, MA: Abt books, 1979.

Kerlinger, F. N., and Pedhazur, E. J. Multiple regression in behavioral research. New York: Holt, Rinehart, \& Winston, 1973.

Kunin, T. "The construction of a new type of attitude measure." Personnel Psychology, 1955, pp. 65-78.

Landy, F. J., and Guion, R. M. "Development of scales for the measurement of work motiva. tion." Organizational Behavior and Human Performance, 1970, pp. 93-103.

Lodahl, T. M., and Kejner, M. "The definition and measurement of job involvement." Journal of Applied Psychology, 1965, pp. 24-33.

Lyons, T. F. "Role clarity, need for clarity, satisfaction, tension and withdrawal." Organizational Behavior and Human Performance, 1971, pp. 99-110.

McClelland, D. C. "Business drive and national achievement." Harvard Business Review, 1962, pp. 99-112.

McNemar, Q. Psychological statistics, 3rd ed. New York: Wiley, 1962.

Maslow, A. H. Motivation and personality. New York: Harper, 1954.

Meade, R. D., and Whittaker, J. D. "A cross-cultural study of authoritarianism." Journal of Social Psychology, 1967, pp. 3-7.

Mosier, C. I. "Problems and designs of cross-validation." Educational and Psychological Measurement, 1951, pp. 5-11. 
Nath, R. "A methodological review of cross-cultural management research." International Social Science Journal 20 (1968), pp. 37-61.

Olkin, J., and Pratt, J. W. "Unbiased estimation of certain correlation coefficients." Annals of Mathematical Statistics, 1958, pp. 201-211.

Price, J. L. Handbook of organizational measurement. Lexington: D. C. Heath, 1972.

Porter, L. W.; Steers, R. M.; Mowday, R. T.; and Boulian, P. V. "Organizational commitment, job satisfaction, and turnover." Journal of Applied Psychology, 1974, pp. 603-609.

Quinn, R. P., and Shepard, L. J. The quality of employment survey. Ann Arbor: Survey Research Center, 1974.

Roberts, K. H. "On looking at an elephant: An evaluation of cross-cultural research related to organizations." Psychological Bulletin, 1970, pp. 327-350.

, and Snow, C. C., eds. "A symposium: Cross national organizational research." Industrial Relations, 1973, pp. 137-247.

Sekaran, U. "Are U.S. organizational concepts and measures transferable to another culture: An empirical investigation." Academy of Management Journal 24 (1981), pp. 409-417).

Sims, H. P.; Szilagyi, A. D.; and Keller, R. T. "The measurement of job characteristics." Academy of Management Journal, 1976, pp. 195-212.

Smith, P. C.; Kendall, L.; and Hulin, C. The measurement of satisfaction in work and retirement. Chicago: Rand McNally, 1969.

Steers, R. M., and Braunstein, D. N. "A behaviorally-based measure of manifest needs in work settings." Journal of Vocational Behavior, 1976, pp. 251-266.

Statistical Outline of India. Tata Services Limited, Department of Economics and Statistics, 1980.

Wagner, F. R., and Morse, J. J. "A measure of individual sense of competence." Psychological Reports, 1975, pp. 451-459.

Wagner, F. R. Personal Communication, 10 April 1978.

Weber, S. J., and Cook, T. D. "Subject effects in laboratory research: An examination of subject roles, demand characteristics, and valid inference." Psychological Bulletin, 1972, pp. 273-295.

White, J. K., and Ruh, R. A. "Effects of personal values on the relationship between participation and job attitudes." Administrative Science Quarterly, 1973, pp. 506-514.

Whitting, J. W. M., and Child, I. L. Child training and personality. New Haven: Yale University Press, 1953.

Wiggins, J. S. "A psychological taxonomy of trait-descriptive terms: The interpersonal domain." Journal of Personality and Social Psychology, 1979, pp. 395-412.

Zucher, L. A. "Particularism and organizational position: A cross cultural analysis." Journal of Applied Psychology, 1968, pp. 139-144. 